\title{
Robust Indicators of Nonproliferation Performance
}

MR Cowan

AJ Kurzrok

February 2014

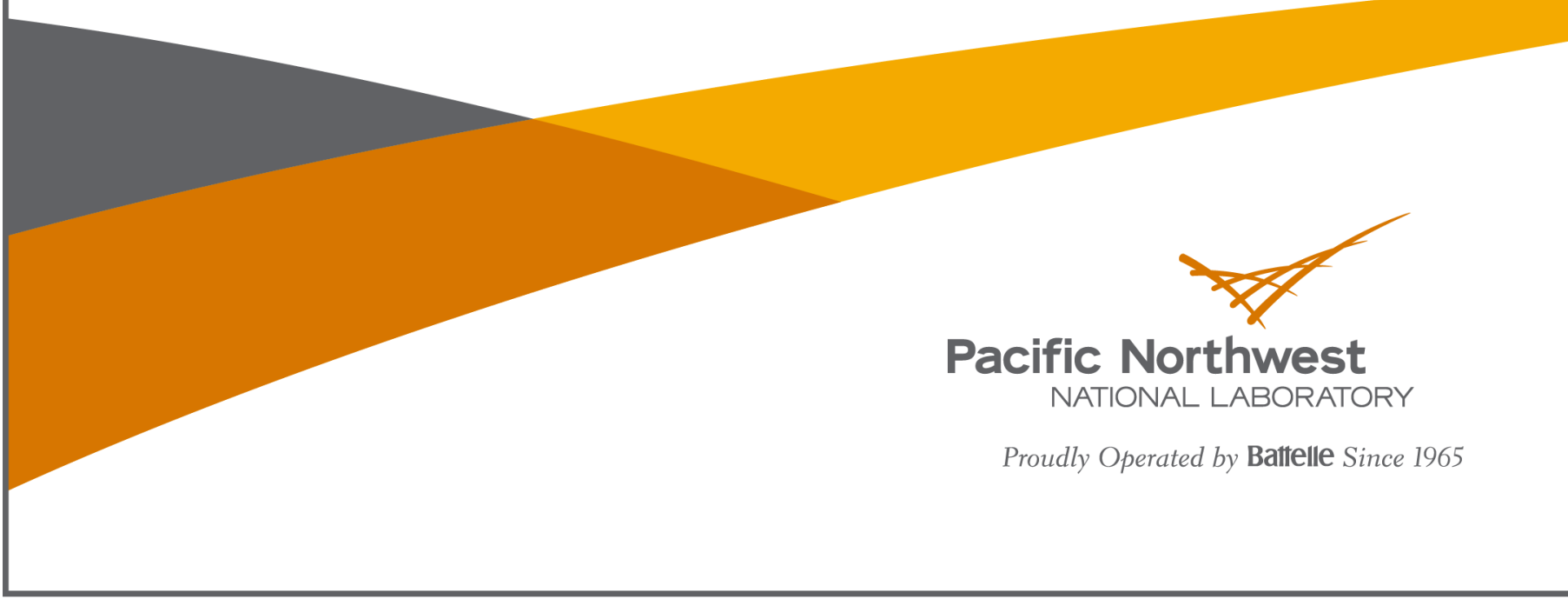




\title{
DISCLAIMER
}

This report was prepared as an account of work sponsored by an agency of the United States Government. Neither the United States Govemment nor any agency thereof, nor Battelle Memorial Institute, nor any of their employees, makes any warranty, express or implied, or assumes any legal liability or responsibility for the accuracy, completeness, or usefulness of any information, apparatus, product, or process disclosed, or represents that its use would not infringe privately owned rights. Reference herein to any specific commercial product, process, or service by trade name, trademark, manufacturer, or otherwise does not necessarily constitute or imply its endorsement, recommendation, or favoring by the United States Government or any agency thereof, or Battelle Memorial Institute. The views and opinions of authors expressed herein do not necessarily state or reflect those of the United States Government or any agency thereof.

\author{
PACIFIC NORTHWEST NATIONAL LABORATORY \\ operated by \\ BATTELLE \\ for the \\ UNITED STATES DEPARTMENT OF ENERGY \\ under Contract DE-AC05-76RLO1830 \\ Printed in the United States of America \\ Available to DOE and DOE coetractors from the \\ Omice of Scientific and Technical Information, \\ P.O. Bos 62, Oak Ridge, TN 37831-0062: \\ ph: (865) 576-8401 \\ fax: (865) 576-5728 \\ email: reportseadonis,osti.gov \\ Avallable to the pablic from the National Technical Information Service \\ 5301 Shawnee Rd., Alexandria, VA 22312 \\ ph: (800) S53-NTIS (6847) \\ email: oxdersantis, gov <hitp://www.ntis,gov/about/form.asps> \\ Online ordering: http://www,ntis,gov
}

fif This document was printod on recycled paper.

(8/2010) 
PNNL-23146

\section{Robust Indicators of Nonproliferation Performance}

MR Cowan

AJ Kurzrok

February 2014

Prepared for

the U.S. Department of Energy

under Contract DE-AC05-76RL01830

Pacific Northwest National Laboratory

Richland, Washington 99352 

The private sector has an essential role to play in protecting global supply chains from misuse towards nuclear weapons production. Proliferation procurement agents continue to target the manufacturers, suppliers, shippers, brokers, and financiers of nuclear and dual-use commodities as unwitting participants in their purchasing schemes. To help combat the spread of these weapons, industry can go beyond its minimum legal obligations with self-regulatory activities. ${ }^{1}$ These activities decrease risk and contribute to overall corporate sustainability practices. $^{2}$

PNNL's interviews with companies in the nuclear and dual-use manufacturing industries have revealed that they realize few, if any, rewards from the government or their supply chain partners for excelling on nonproliferation. Often, the strongest incentive for a company to protect against spreading nuclear weapons-related materials and technologies is simply to avoid penalties. Even for those firms that see nonproliferation excellence as a national security duty, there is no private benefit for going beyond basic compliance with export control laws. According to Melissa Mann, a manager at uranium enricher URENCO, "In my marketing experience I have never been given credit for being a good nonproliferation player." ${ }^{3}$

A lack of tangible return on nonproliferation investment makes it difficult for compliance teams and management to advocate for additional resources to improve nonproliferation business practices or, in the worst case, to even take export compliance seriously. Without an external incentive, it is difficult to encourage companies to take steps such as: ${ }^{4}$

- Maintaining an export management and compliance program

- Sharing tips about suspicious orders with government agencies, and, if appropriate, other firms

- Preferentially contracting with supply chain partners that also maintain high nonproliferation standards

- Supporting industry-led activities to develop export control compliance best practices or nonproliferation advocacy

- Participating in governmental export control rulemaking

Despite this experience for proliferation supply chain firms, there are potential economic motivators for businesses to increase their self-regulation in nonproliferation. These include reducing legal/regulatory, reputational, financial, and criminal risks as well as the opportunity to gain market share. Sectors such as apparel manufacturing, diamonds, chemicals, tuna fishing, and nuclear power have realized gains from taking steps that go beyond the regulatory requirements. ${ }^{5}$

Better information could change this trend for firms at risk of proliferation, as it has for other sectors. Stakeholders such as capital markets, creditors, consumers, supply chain partners, and governments are increasingly holding companies accountable for the ways in which they define and implement corporate strategy. These parties could incentivize companies to go beyond compliance by preferentially choosing those that performed well as nonproliferators.

Unfortunately, it is challenging for a company to fully know whether it is managing its proliferation risks well or is simply lucky that it has not made a mistake or been caught yet. Declaring a company's nonproliferation program "effective" requires proving a negative; it is impossible to affirmatively state that a company's operations have not contributed to proliferation. However, even if certainty is unattainable, companies can still develop strong evidentiary indicators that their efforts not to proliferate are working. 
This white paper explores indicators that would enable companies to show their internal and external stakeholders that they maintain a strong nonproliferation program that takes appropriate steps to reduce the chance that the company will spread nuclear-useable goods, services, and technologies. Ultimately, reporting on these indicators can provide the marketplace with information necessary to better reward those that invest in nonproliferation excellence.

\section{Measuring Effective Performance}

Understanding how these sectors may benefit from self-regulation is closely linked with understanding how to report on nonproliferation objectives, as well as where to set the bar to be viewed as high nonproliferation performer. The corporate sustainability reporting model is a framework that nuclear and dual-use sectors can use to plan, measure, and report on their self-regulatory activities.

Increasingly considered part of a firm's broader approach to governance, risk mitigation, and compliance, corporate sustainability programs can respond to long-term risks to business and near-term demand from consumers for sustainable products. Robust sustainability programs are complex and ongoing, and offer a constantly-improving set of policies, procedures, and performance metrics to reduce corporate risk. Open reporting on standardized metrics can permit internal and external stakeholders to assess how well a given company is meeting its sustainability goals and commitments. Due to evolving consumer expectations and emerging corporate norms, voluntary sustainability reporting has become increasingly common. Though nonproliferation is not a part of regular sustainability reporting today, companies in relevant industries could eventually incorporate it into their reporting.

Despite the accepted benefits of broad reporting, measuring performance is a challenge for managers across all industries. This is particularly true for compliance, a field in which it is impossible to discount "unknown unknowns." In fact, 31 percent of industry respondents to a survey published by Deloitte and the Compliance Week publication said that they do not measure the effectiveness of their compliance programs at all. ${ }^{6}$ Even those companies that do attempt to review their performance struggle. The same industry survey found that, "Of the 63 percent who do try to measure program effectiveness, many of the metrics they use are rudimentary and possibly inadequate." Companies often fall prey to using metrics that simply measure outputs rather than outcomes, or past experiences rather than future risks.

Developing relevant, responsive metrics is an area of close study in sustainability, risk management, and compliance. The enormous growth in reporting in the past decade has led to stakeholder expectations of an overwhelming number of measurements. While some measurements should be closely watched for performance anomalies, others seem less germane. For example, fair labor practices may be a critical metric for a coffee importer, but it is less of a concern for a U.S.-based engineering services firm. Yet reporting practices can fail to capture this distinction: for a company's sustainability report to receive an " $A$ " grade under the Global Reporting Initiative (GRI) methodology, the company must report on each metric in GRI's framework.

In recent years, researchers have questioned whether comprehensive reporting is the best use of corporate resources, rather than focusing on the few issues that have the greatest sustainability impacts. This has led to the notion of "key performance indicators" (KPIs). These metrics are both comprehensive and relevant without being overly burdensome to report. Additionally, KPIs permit stakeholders to benchmark data and compare companies within the same sector, particularly if the metrics are consensus-based or defined and monitored by a third party. 


\section{KPIs for Nonproliferation (nuclear and dual-use industries)}

The many types of firms that play a role in stopping the spread of nuclear weapons face a host of sustainability challenges, of which nonproliferation may represent just one. As companies seek to distinguish themselves through nonproliferation leadership or to demonstrate proactive compliance with export control regulations, their nonproliferation policies and procedures must be measured against indicators to provide assurance that their commitments are being met.

A recent Harvard University study ${ }^{7}$ outlined a six-step method for identifying key performance indicators on corporate sustainability impacts in specific industries. Applying this methodology to determine the most relevant areas of measurement within the nuclear and dual-use sectors, we catalogued nonproliferation opportunities and risks within dual-use commodity sales, shipping practices, standards and codes of conduct, and supply chains. Ranking these opportunities and risks against criteria including financial impacts, legal/regulatory/policy drivers, business peer based norms, stakeholder concerns, and opportunities for innovation, we found that the most material nonproliferation challenges to these sectors are combating the illicit procurement strategies of would-be proliferators. To this end, we sought to target five "proliferation pathways" that guided the development of the KPIs: ${ }^{8}$

1. Supplier ships directly to proliferation end user;

2. Supplier ships to presumed legitimate end user, who reships to proliferation end user;

3. Supplier ships to intermediary (broker, freight forwarder, trading company, etc.) who reships to proliferation end user;

4. Supplier ships to presumed legitimate end user, but shipment is re-routed in transit to a proliferation end user;

5. Supplier ships directly to legitimate end user, who also uses the goods for proliferation purposes

The specific commercial norms of a supplier's sector may make one or more pathways likely to occur; the indicators we suggest are designed to be broad enough that all companies within the nuclear and dual-use industries should be able to report on them. Robust indicators will measure both policy and procedure, and focus on activities, process, and outcomes for both standard practices and innovative areas for improved sustainability. If appropriately developed, use of these indicators within a performance measurement system allow for increased cross-company transparency and "apples-toapples" comparisons of corporate performance. Table 1 correlates these proliferation pathways with the most suitable proposed KPIs to measure a company's ability to counter that threat.

While KPIs do not measure whether a company's nonproliferation program is completely effective, they can still prove beneficial to companies. These KPIs measure the processes and procedures by which industry consensus has agreed make it unlikely that a company is contributing to proliferation. Over time, using these indicators, companies can narrow their reporting to information that proves material in nonproliferation, and benchmark the incidences of proliferation to the output indicators. This measurement can help these companies distinguish themselves as a "good nonproliferators," reaping market-based benefits such as increased sales from improved reputation.

Drawing on the indicators suggested in PNNL's 2013 Bulletin of the Atomic Scientists article as well as best practices developed through several other recent efforts, ${ }^{9}$ we propose the following KPIs for the nuclear and dual-use industries to report on their nonproliferation practices: 
- Corporate statement on nonproliferation: companies publish an executive-led policy to adhere to nonproliferation business practices. All lower level policies and operational procedures are aligned with this policy. Having a policy is an indication of a good nonproliferator.

- Internal compliance program: companies implement internal compliance programs based on best practices outlined by the Coalition for Excellence in Export Compliance; U.S. Department of Commerce, Bureau of Industry and Security; Nuclear Suppliers Group; or equivalent bestpractice guides. Having a well-developed program is an indication of a good nonproliferator.

- Number of export control violations: companies report violations, including any civil or criminal penalties and the action that triggered the violation. Fewer reported violations (or smaller percent based on overall sales) are an indication of a good nonproliferator.

- Number of meetings with government on regulations: companies report the number of times it engaged government on understanding updated regulations, improving regulations, or improving implementation/ compliance. Greater engagement with government on regulatory practices may be an indication of a good nonproliferator.

- Percentage of post-shipment verification: companies report the percentage of sales that are verified after shipment to ensure end user and end use is legitimate and as reported. Significant follow-up on end users is an indication of good nonproliferation.

- Number of suspicious order tips: companies report how many tips on suspicious orders were shared with government (or third party) entities. Indicative of employee attitudes toward compliance, submission of a greater number of tips may be an indication of a good nonproliferator.

- Percentage of employees trained on export control compliance: companies report percentage of employees receive training on export control compliance and due diligence procedures. More employees trained on export control compliance are an indication of a good nonproliferator.

- Maintain database of suspicious inquiries and unverified end users: companies report on whether they track suspected proliferators, procurement agents and/ or untrustworthy shippers or intermediary agents. Having a database is an indication of a good nonproliferator.

- Percentage of employees who can identify risks/ red flags: companies report on assessments of employees who have taken proliferator risk training to indicate percent who can identify risks and red flags. Internal audits, employee surveys, and periodic evaluation are examples of potential assessment tools . Further, measuring employees' willingness to report suspicious orders may be considered. Greater percentage of target employees who can identify proliferation risks is an indication of a good nonproliferator.

- Supply chain due diligence procedures: companies report on whether they have and implement due diligence procedures to check on their supply chain, shippers, and end users. Having due diligence procedures is an indication of a good nonproliferator and is an area for innovation within the industry. 
- Information sharing of suspected proliferators: companies report whether they share their database of suspected proliferators, procurement agents and/ or untrustworthy shippers or intermediary agents with government entities or third parties. This information sharing is an indication of a good nonproliferator and is an area for innovation within the industry.

- Corporate policy not to ship to middlemen: companies report whether they have a policy not to ship to middlemen, such as trading companies, who have a greater risk for shipping to proliferators, or being opaque about where products truly end up. Such a policy is an indication of a good nonproliferator and is an area for innovation within the industry.

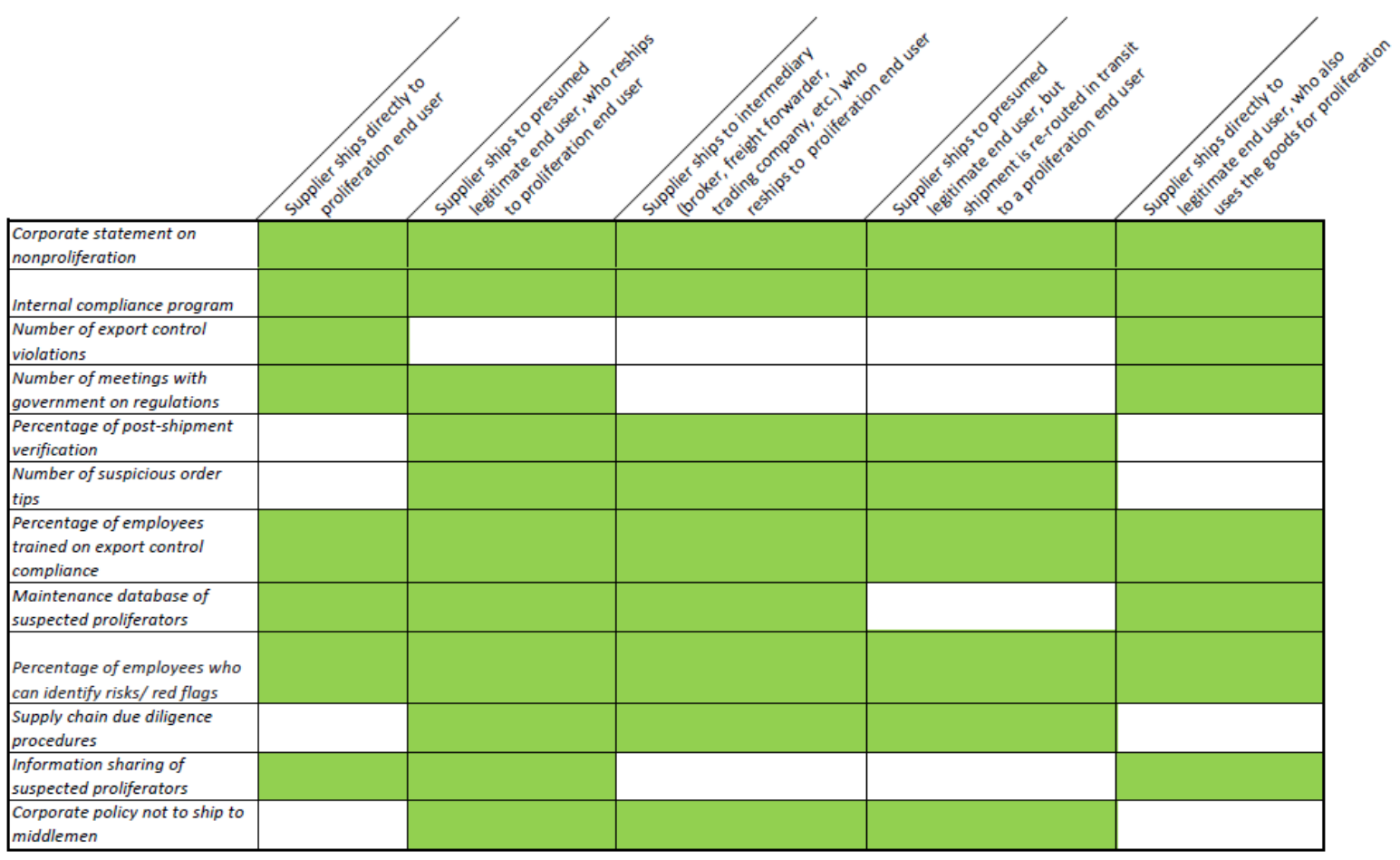

Table 1: Proliferation pathways and suitable KPIs

Companies that measure and report on their performance must undertake a process of benchmarking their performance and refining indicators through procedural changes after proliferation events. Still, it is important to recognize that all companies may not answer based on identical practices, or be able to report on all KPIs. However, reporting on all KPIs, or a combination, will increase stakeholders' confidence about the validity of the performance measure. Further discussion with industry leaders will contribute to identifying the minimum necessary number of KPIs that companies of varying size can commit to report on. Identifying the appropriate level of reporting can be modeled after other marketdriven sustainability reporting protocols like GRI or the Forest Stewardship Council, which also sets standards for sustainability excellence, offers certifications and contributes to product labelling for sustainably-produced wood products. ${ }^{10}$ 


\section{Conclusion}

Over time, KPIs can help companies show others that their nonproliferation programs work. Effective metrics-based performance measurement supports both internal and external auditors to know which data to look for, and can permit a company to embed ongoing monitoring of the same indicators into regular operations, reducing the burden of auditing and allowing for continual process improvement.

When developed through a consensus approach and agreed to by industry leaders, companies can establish indicators that clarify which firms meet an absolute bar for good performance or have relatively good performance when compared to other firms. A "Good Housekeeping Seal of Approval" concept, based on an overall performance metric, or a comparative distinction, like placement on the Dow Jones Sustainability Index ${ }^{11}$ can help companies message their good performance to both regulators and consumers.

It is important to note that without a perceived demand for KPI information, companies are unlikely to expend critical resources to develop it. Regulators may have a unique role to play as the first to reward effective nonproliferation performance and reporting. It may be appropriate to provide certain regulatory relief (i.e., faster licenses, longer license periods) to firms that report on strong nonproliferation performance and therefore lower proliferation risk. With this competitive advantage, such firms may be better positioned to convince supply chain partners such as financiers and insurers that they present lower risks of default or compliance failure. As benefits accumulate to participating firms, the relative costs of non-participation would increase. This dynamic could overcome the lack of perceived demand and move whole sectors to lower their proliferation risks and report on their activities.

Today, external stakeholders do not often reward fuel cycle companies like URENCO or dual-use commodity suppliers for being strong nonproliferators. Though most companies hopefully will continue to "do the right thing," the lack of support from others need not be the case. Transparency and information in other sectors have enabled those companies to benefit from reducing non-financial risks similar to proliferation. As rewards begin to materialize for companies at risk of contributing to proliferation, a shift in thinking from terms of "compliance" to "corporate risk management" may allow companies to better incorporate nonproliferation into everyday business and corporate strategy.

\footnotetext{
${ }^{1}$ Several authors have called for industry to go "beyond compliance." See Stewart, lan J. and John McGovern, "Beyond Compliance: Preventing the Diversion of Sensitive Vacuum Measuring Equipment - "The Controlled Delivery Model," CSSS Occasional Papers 3/2013, King's College London, September, 2013, accessed January 31, 2014, http://www.kcl.ac.uk/sspp/departments/warstudies/research/groups/csss/pubs/beyondcompliance.pdf and Olson, Nate and Brian Finlay, "Market Power: Adapting Public and Private Roles for Transnational Commerce and Transnational Threats," Stimson Center, September, 2013, accessed January 31, 2014, http://www.stimson.org/images/uploads/research-pdfs/Market_Power_Sep2013.pdf.

${ }^{2}$ Corporate sustainability programs are an industry approach to addressing how business practices impact a company's economic outlook, environment, and social and human rights.

3 "New Nuclear Suppliers Part 2." YouTube. Video file, 46:37. Posted by Center for Strategic \& International Studies, December 13, 2013. Accessed January 27, 2014. http://www.youtube.com/watch?v=f75CO YFoAO.
} 
${ }^{4}$ These steps were discussed in greater length in Kurzrok, Andrew. Market-Driven Nonproliferation: Leveraging competitive advantage in support of U.S. policy. Washington, DC: Pacific Northwest National Laboratory, 2013.

${ }^{5}$ These sectors have undertaken activities to mitigate potential negative externalities posed by their operations. For example, the apparel industry, facing the challenge of reputational risk posed by its use of cotton picked by Uzbek child labor established the Cotton Pledge to mitigate damages. Similarly, in the diamond industry, the Kimberley Process has become a flagship program for reducing the mining and sales of conflict stones.

6 "In Focus: Compliance Trends Survey 2013," Deloitte and Compliance Week, August 2013, accessed January 28, 2014, http://www.deloitte.com/assets/Dcom-

UnitedStates/Local\%20Assets/Documents/AERS/us aers dcrs final deloitte compliance week 111913.pdf.

${ }^{7}$ Lyndenberg, Steve, Jean Rogers and David Wood. From Transparency to Performance: Industry-Based

Sustainability Reporting on Key Issues. Cambridge, MA: Initiative for Responsible Investment, 2010. Available: http://www.sasb.org/wp-content/uploads/2012/03/IRI Transparency-to-Performance.pdf

${ }^{8}$ While these five may not represent a comprehensive catalog of proliferation pathways, public record prosecution documents of cases of suspected proliferators commonly illustrate these pathways to undermine export regulations.

${ }^{9}$ Kurzrok, Andrew and Gretchen Hund. "Beyond Compliance: Integrating nonproliferation into corporate sustainability." Bulletin of the Atomic Scientists 69, no. 3 (May/June 2013): 31-42; Good Practices for Corporate Standards to Support the Efforts of the International Community in the Non-proliferation of Weapons of Mass Destruction. Nuclear Suppliers Group, 2013. Available http://www.nuclearsuppliersgroup.org/A test/01eng/NSG\%20Measures\%20for\%20industry\%20update\%20revised\%20v3.0.pdf. BIS "Best Practices for Industry to Guard Against Unlawful Diversion through Transshipment Trade, Bureau of Industry and Security, 2013. Available https://www.bis.doc.gov/index.php/forms-documents/doc view/625-best-practices

${ }^{10}$ The Forest Stewardship Council (FSC) offers two kinds of certifications and a variety of standards. Variable certifications permit companies with dissimilar resources can "right size" the kind of distinction they seek from demonstrating performance excellence. For more on the FSC, see https://us.fsc.org/who-we-are.176.htm. ${ }^{11}$ The Dow Jones Sustainability Index (DJSI) evaluates the sustainability performance of over 2500 of the largest globally traded companies. Based on initial and ongoing Corporate Sustainability Assessments (a proprietary assessment by the private company, Robesco SAM), the DJSI lists the top 10\% performing companies in each of 58 industries. The Corporate Sustainability Assessment uses defined criteria to evaluate economic, environmental, and social dimensions, which are combined measure a total sustainability score. Companies that score poorly in ongoing assessments/ monitoring are excluded from the annual Corporate Sustainability Assessment and are not maintained in the DJSI. 



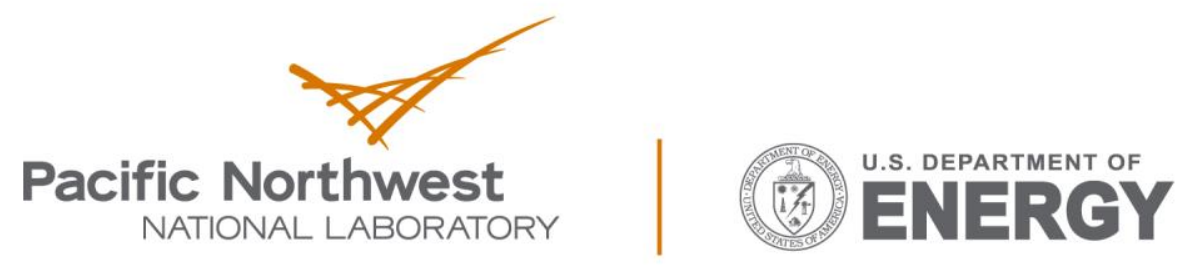

Proudly Operated by Battelle Since 1965

902 Battelle Boulevard

P.O. Box 999

Richland, WA 99352

1-888-375-PNNL (7665)

www.pnnl.gov 